\title{
The Theoretical Defenses Of The Last In First Out Inventory Methods
}

Peter Harris, New York Institute of Technology, USA

William Stahlin, Stevens Institute of Technology, USA

\begin{abstract}
The Last in First out Method (LIFO) is presently under severe scrutiny from the financial community which may soon culminate in its repeal as an acceptable accounting method. There are pressures from the SEC in conjunction with the International Financial Accounting Standards Board (IFRS) to standardize accounting standards worldwide. In addition, there is political pressure imposed by the U.S. administration to raise additional revenues. Both groups strongly oppose LIFO, raising a strong possibility of its complete elimination. This paper addresses the reasons defending LIFO as an acceptable accounting method strictly from a financial reporting perspective.
\end{abstract}

Keywords: LIFO; LIFO Reserve; FIFO; IFRS

\section{INTRODUCTION}

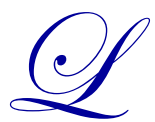

IFO can be defended from a financial accounting reporting standpoint as this paper explores. Further, IFRS introduces several limitations and criticisms not evident in LIFO, further defending LIFO's position as an acceptable accounting method. This paper examines the defenses of LIFO, the current and future states of LIFO, and the defenses of LIFO from a financial reporting perspective, which include the following aspects. First, from an accounting theory perspective, it satisfies the principles of matching and the income statement economic reality of LIFO presentation. Additionally, a correct Balance Sheet amount can also be derived by use of the LIFO by utilizing the required LIFO Reserve disclosure. It also adheres to the historical cost and conservatism principles. Second, from the perspective IFRS, there is a deviation from historical cost which allows for estimation of values, resulting in the possibility of earnings management by the use of the Lower of Cost or Market rule. The Conclusion section will give the limitations of the paper and recommend future research in this area.

\section{THE CURRENT AND FUTURE STATES OF LIFO}

LIFO is facing pressures from both the International Reporting Standards Board in cooperation with the SEC and the U.S. Congress for its possible complete elimination by as early as calendar year 2014. On November 15, 2007, the Securities and Exchange Commission (SEC) exempted foreign firms from including reconciliation from International Financial Reporting Standards (IFRS) to U.S. Generally Accepted Accounting Principles (U.S. GAAP) when filing on U.S. Stock exchanges. Foreign public firms are now permitted to file using the International Financial Reporting Standards (IFRS) without reconciliation to U.S. GAAP as previously required. This move has created a mandate to converge IFRS and U.S. GAAP and financial statement requirements (SEC, 2007).

On June, 18, 2008, the SEC issued a press release stating that the world's securities regulators are uniting to increase their oversight of international accounting standards. Most of the developed countries, such as Australia, New Zealand, Canada and the European Community Union, have adapted IFRS by the year 2011.Under IFRS rules, LIFO is not a permitted acceptable accounting method. IFRS is balance sheet oriented and, on this basis, disallows LIFO as an inventory method. The use of LIFO disrupts the theoretical foundation of the IFRS and if plans proceed as expected, complete phase-out of LIFO will occur in the near future. More importantly is the current tax position on LIFO. The Obama Administration has proposed in its 2010 budget to repeal LIFO altogether in an attempt to generate greater tax revenues. 
However, recent developments have helped LIFO's future. First, the worldwide economic crisis is persisting. Second, Senator Rangel, the greatest opponent of LIFO has been charged with ethical violations, resulting in his backing off from LIFO repeal. His opposition to LIFO is now a mere footnote. Additionally, the persisting and exaggerated European Crisis has questioned the role of accounting as a cause of an economic downturn as IFRS has been adapted in the European Community countries. This questions the need of IFRS and conformity as a saving grace in the world economies. Most significantly, the SEC has recently continued to exhibit excessive non-enthusiasm in the convergence map, making IFRS compliance unlikely at this time. This all adds to renewed hopes for LIFO and, at a minimum, extends its life expectancy into the indefinite future and far beyond the IFRS original proposed adaption date of December 31, 2014.

\section{DEFENSES OF LIFO}

LIFO can be defended on present accounting theory, which can transform LIFO use to correct income statement financial reporting totals, as discussed next. It can also be defended that LIFO reserve disclosure can most accurately transform the Inventory balance sheet value to the most current cost presentation. Lastly, IFRS suffers in many areas of financial reporting, including the deviation from historical cost which leads to earnings management possibilities not found in LIFO.

\section{Accounting Theory}

1. LIFO satisfies many present underlying U.S. GAAP principles, including the matching principle which results in an Income Statement economically reality presentation. LIFO's greatest defense is that the Income Statement represents economic reality as it matches current inventory cost with current revenue, making the Income Statement correct. The matching principal is adhered to by LIFO use. However, the matching principle will only apply if there is a build-up of inventory reserves. If there is a liquidation of inventory, then matching will not occur as there will be predated, older inventory matched to current revenue. An example will illustrate this point.

Example: Assume Corp X had the following:

Beginning Inventory

Purchase

Total
10 units $@ \$ 20$ per unit $=\$ 200$
$\frac{90 \text { units }}{100 \text { units }} @ \$ 40$ per unit $=\underline{\$ 3,600}$

If ending inventory is 15 units; i.e., 85 units sold @ \$60 per unit, we have a "correct" LIFO Income Statement as follows:
Sale
$\$ 5,100$
(85 units X \$60)
Cost of Goods Sold
$\$ \underline{(3,400)}$
(85 units $X \$ 40)$
Gross Profit
$\$ 1,700$
85 units $X \$ 20$

Gross Profit $\%=$ Sales-Cost of Sales Sold $) /$ Sales $=33 \%$.

This is the correct Income Statement as there is a build-up/maintenance of inventory. Current revenue is matched only with current purchases. However, in the case of liquidation, if for example ending inventory is two units; i.e., 98 units sold, we are expensing current purchases of $\$ 40$ each, plus older purchases of $\$ 20$ each against current revenue. The Income Statement now is not reflective of economic reality. The result using LIFO is:
Sales
$\$ 5,880$
(98 units x \$60)
Cost of Goods Sold
$\$ 3,760(2)$
Gross Profit
$\$ 2,120$
(2) $(90 \times \$ 40)=\$ 3,600$
$+\quad(8 \times \$ 20)=\underline{160}$
$\$ 3,760$ 
The Gross Margin Profit \% (Sales-Cost of Goods Sold/Sales) here is $\$ 2,120 / 5,880=36 \%$ substantially higher than the reality of 33\% (1), resulting in an unreal Income Statement.

However, even if this liquidation were to occur, the SEC and U.S. GAAP require disclosure of the effect on earnings resulting from this liquidation. As such, matching is restored and current cost is matched with current revenue, ensuring an Income Statement reality presentation. In this situation, the effect of LIFO liquidation is $\$ 160$, derived from the liquidation of eight units times the difference in current cost and the cost of beginning inventory of $\$ 20$. The result is:
Sales
$\$ 5,880$
Cost of Goods Sold
$\$ \underline{3,920}$
Gross Profit
$\$ \underline{1,960}$
(98 units $\mathrm{x} \$ 60$ )
( $\underline{3,760 \text { plus } 160=\text { liquidation effect of LIFO) }}$

This resulting decrease in income of $\$ 160$ via LIFO liquidations needs to be disclosed under U.S. GAAP rules, ensuring proper income presentation of LIFO use.

2. Balance Sheet Correcting Inventory total by use of the LIFO Reserve amount: Since LIFO expenses its most recent inventory acquisitions to cost, the ending inventory balance presentation is composed of the oldest inventory purchases, making the balance sheet potentially and practically very inaccurate. From a non-tax aspect, this is the most viable argument against LIFO. An example will illustrate this shortcoming: if Exxon- Mobil purchased 20,000 barrels of oil in 1939 for $\$ 5$ per barrel and the 20,000 barrels remained in the accounting records as ending inventory in 2012, when the cost per barrel is $\$ 100$ - an assumption which is easily satisfied assuming an increasing inventory trend, then the LIFO balance sheet total for inventory in 2012 is materially misstated. Under LIFO, ending inventory in 2010 is 20,000 barrels $x \$ 5=$ $\$ 100,000$ (1939 prices), whereas the more accurate valuation, which would be reflected under FIFO, is 20,000 barrels x $\$ 100=\$ 2,000,000$ (most current prices), resulting in an understatement of $\$ 1,9000,000$ or $95 \%$ of asset value. LIFO produces unrealistic Balance Sheet Inventory totals when compared to economic reality. LIFO is too conservative and yields unrealistic financial totals for inventory, current assets, total assets, net income and Shareholders' Equity.

The saving grace, however, is that LIFO use can depict a true, current inventory valuation by use of the required IFO Reserve disclosure. The LIFO Reserve is simply the difference between the LIFO and FIFO inventory value. In our example, FIFO would reflect an ending inventory of 20,000 barrels $X \$ 100$, or $\$ 2,000,000$, and LIFO would reflect a total of $\$ 100,000$, resulting in a required disclosed LIFO Reserve of $\$ 1,900,000$. A FIFO Balance Sheet friendly total can easily be calculated by adding the LIFO Reserve; in this case, one may add the disclosed reserve amount of $\$ 1,900,000$ to the LIFO inventory total, resulting in a Balance Sheet current cost value of $\$ 2,000,000$.

Any type of ratio analysis involving Balance Sheet inventory valuation should use this corrected inventory FIFO amount as its base. As the following examples illustrate, if we wanted to calculate Return on Assets = EBIT/Assets, the asset base should include inventory on the FIFO basis. In terms of debt ratio $=$ Liabilities/Assets, again, the asset base should include inventory on the FIFO basis. The use of LIFO in asset, including inventory type ratios, can be correct by virtue of the adjustment to FIFO, via the LIFO reserve. This should be and can easily be done prior to calculating, interpreting and commenting on Balance Sheet related ratios.

1. Conservatism: LIFO presents the most conservative financial position of a company. In an age of inflating earnings, LIFO is a relief in this regard and adheres to the principles of U.S. GAAP.

2. Historical Cost: Further, the goal of reliability is met by LIFO use as historical cost valuation is followed. This is consistent with U.S. GAAP methodology.

\section{IFRS Limitations}

Both U.S. GAAP and IFRS allow for the Lower of Cost or Market for the valuation of inventories. This can be coupled with the FIFO or Weighted Average Method of inventory accounting. Under U.S. GAAP, LCM cannot be used if LIFO is the chosen accounting method. 
Market is usually defined as replacement cost under U.S. GAAP and Net Realizable value, sales price less the cost of disposal under IFRS. IFRS will yield the higher market value. Lastly, IFRS rules allow for losses to be reversed if market value increases; however, U.S. GAAP does not allow reversal of losses under any circumstance.

The potential negative implications under IFRS are as follows:

1. A deviation from historical cost: By allowing the LCM, subjective values can be imposed in the valuation of non-LIFO inventory, leading to earnings management and potential income manipulation practices. Further, LCM can be applied on an inventory total basis, a unit-by-unit basis, or by inventory groupings, further igniting income manipulation reporting.

2. Earnings management potential as losses are allowed to be reversed in a future period: This can be quite problematic and companies can easily create "income" simply by reversing inventory losses, assuming an increase in market values by controllable in-house, subjective valuations. Additionally, one can increase income by reversing LCM losses simply by reducing year-end inventory totals. As an example, if a corporation had an inventory loss of $\$ 50$ as a result of LCM losses, this amount can be reversed simply by having a zero balance inventory amount at year-end - a policy within the control of the entity. This is too easy and the results of earnings management are thus controllable within the company.

Use of LIFO will prevent the above limitations, as LIFO use is objectively based and disallows the LCM rule, which may become very problematic in financial reporting under IFRS. Under U.S. GAAP, if a company uses LIFO, it is precluded from using LCM and, in effect, retains the historical cost principle, preventing potential earnings shenanigans.

\section{CONCLUSION}

LIFO can be defended on many aspects of accounting theoretical frameworks, including the matching principle, historical cost principle, conservatism, reliability and relevance. Under LIFO, the Income Statement depicts a correct economic picture of a company's operations. The ability to present a correct Balance Sheet amount by use of the required LIFO Reserve amount is also easily possible, making the Balance Sheet economically relevant. Additionally, IFRS suffers from several key theoretical perspectives, such as the deviation from historical cost, reversal of previous year's inventory losses, and subjectivity as to calculation of market value, consequently allowing for the possibility of practicing earnings management techniques not evident in LIFO. The limitation of this paper is the ultimate repeal of LIFO which, although not presently likely, is possible. Further research should focus on the argument against LIFO as well as other non-accounting defenses of LIFO.

\section{AUTHOR INFORMATION}

Peter Harris is a Professor of Accounting and Finance at the New York Institute of Technology, and is the Chair of the Accounting and Finance Department. He has more than 125 intellectual contributions, including over 50 refereed research papers to date. E-mail: pharris@nyit.edu (Corresponding author)

Bill Stahlin is an Affiliate Associate Professor at Stevens Institute of Technology. He has over 30 years of teaching experience and 10 years in public accounting. He is both a CPA and CGMA. He is the mid-Atlantic regional coordinator for the American Accounting Association's teaching, learning and curriculum section. He's made numerous presentations on teaching pedagogy and co-authored an instructor training course while at Coopers \& Lybrand. E-mail: wstahlin@stevens.edu

\section{REFERENCES}

1. Kieso, Weygandt, \& Warfield. (2012). Intermediate accounting $\left(13^{\text {th }}\right.$ ed.). Wiley.

2. $\quad$ PWCoopers.org

3. White, Sondhi, \& Fried. (2008). The analysis and uses of financial statements ( $3^{\text {rd }}$ ed.). Wiley. 